\title{
Translucency of Dental Porcelains
}

\author{
R. H. W. BRODBELT, W. J. O'BRIEN and P. L. FAN
}

The University of Michigan, School of Dentistry, Ann Arbor, Michigan 48109

The translucency of comparable shades of five dental porcelains was determined. Both direct transmittance and total transmittance were measured at wavelengths of $400-700 \mathrm{~nm}$. For $1 \mathrm{~mm}$ of porcelain, the values for direct transmittance were low and averaged 0.13 percent, whereas the values for total transmittance averaged 26.8 percent. Transmittance increased with increasing incident wavelength. These results indicated a high degree of light scattering.

\section{J Dent Res 59(1):70-75, January 1980}

\section{Introduction.}

The widespread use of esthetic porcelain restorations has created the need for a better understanding of the appearance properties of porcelain. The problems of color matching to natural teeth are universally known. It is subject to the limitations of the shade guide, ${ }^{1}$ light source and human perception, ${ }^{2}$ and the colors of the surrounding environment. ${ }^{3-6}$ There are several factors ascribed to the failures in matching shade buttons to natural teeth. One factor is translucency, which is the relative amount of light transmission, ${ }^{7}$ or diffuse reflectance from a substrate surface through a turbid medium.

McLean ${ }^{8}$ discussed the diffuse reflection of light produced by internal scattering and its effect on esthetics. By contrast, the fraction of incident light which emerges as diffuse transmission is considered vital in dental ceramics. The use of gold coatings to increase diffuse reflectance of a porcelainto-metal restoration has been studied by Gettleman et al. ${ }^{9}$ They found an increase in total reflectance, which indicated that a thinner opaque layer can be used, and, thus, requires less reduction of the natural tooth.

There are three methods of studying the translucency of dental porcelain: direct transmission, total transmission (including scattering), and spectral reflectance. It was the purpose of this investigation to study the

Received for publication October 16, 1978 Accepted for publication December 4, 1978

This research was supported by Grant DE 05423 from the National Institute of Dental Research. Bethesda, MD. translucency by direct transmission and total transmission, including scattering, of both the porcelains used in porcelain-fused-tometal restorations and the conventional feldspathic porcelains. We also wanted to study the translucency as a function of wavelength.

\section{Materials and methods.}

Dental porcelains are translucent. The amount of light passing through a translucent material can be approximated as equation 1:

$$
\mathrm{I}=\mathrm{I}_{\mathrm{o}} \mathrm{t}_{\mathrm{c}} \mathrm{x}
$$

for a small range of thickness; where $I_{\text {o }}$ is the intensity of the incident beam; $i$, the intensity passing through the sample; $x$, the thickness of the sample; and $t_{c}$, a constant for the material. ${ }^{10} t_{c}$ is defined as a transmission coefficient, which is the ratio of the intensity of the incident beam and the intensity of the beam passing through a sample of unit thickness.

Light passes through a translucent material by direct transmission and by scattering. The values of $t_{c}$ for direct transmission and total transmission (direct and diffuse) can be measured using appropriate spectrophotometric arrangements (Fig. 1).

The study involved only body porcelains. Five shades were selected using the Bioform shade guide: $* 59,62,65,67$, and 91 . Four porcelains used in porcelain-fused-to-metal systems and one feldspathic porcelain were selected. The products and their equivalent shades used in this study are listed in Table 1.

Four samples were prepared for each porcelain shade. Each sample was prepared by weighing out $0.08 \mathrm{~g}$ of the porcelain, transferred to a stainless steel mold (9.5 $\mathrm{mm}$ diameter $\mathrm{x} 2.9 \mathrm{~cm}$ ) and compressed to $20 \mathrm{MPa}$ in a pneumatic press. The compressed sample was extruded onto a sheet of platinum foil and fired in a porcelain

*Dentsply International, 500 West College Avenue, York, PA 17404

†Dake Corporation, Grand Haven, MI 49417 
A. DIRECT TRANSMISSION

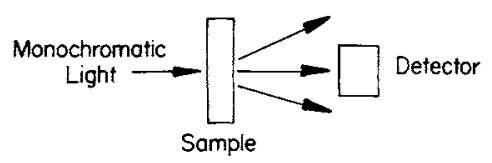

B. TOTAL TRANSMISSION

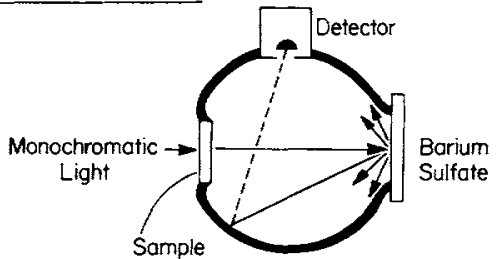

Fig. 1 - Schematic diagrams for (a) direct transmission and (b) total transmission for measuring translucency of dental porcelains using spectrophotometers.

furnace.* Samples for each material were fired simultaneously and as close to one another as practical. The firing procedure was in three stages: preheating, firing, and glazing. Each porcelain sample was fired, as follows, according to the respective manufacturers' instructions.

The Ceramco B.F. vacuum porcelain samples were preheated and inserted into the furnace at $649 \mathrm{C}(1200 \mathrm{~F})$ within five minutes. The samples were then fired under a vacuum pressure of $660-736 \mathrm{~mm}$ (26-29 in) of mercury with an average heating rate of $35 \mathrm{C}(95 \mathrm{~F})$. The vacuum was released and firing continued at the same rate up to $968-982 \mathrm{C}(1775-1800 \mathrm{~F})$. When a high biscuit bake was reached, it was removed immediately and bench cooled. For glazing the samples, the procedure for preheating and firing was repeated up to 982 $\mathrm{C}(1800 \mathrm{~F})$ and bench cooled.

The Vita VMK 68 vacuum porcelain samples were pre-dried slowly in the open furnace at $750 \mathrm{C}(1382 \mathrm{~F})$ for ten minutes. The samples were fired under a vacuum pressure of $635 \mathrm{~mm}$ ( $25 \mathrm{in}$ ) of mercury from $750-960 \mathrm{C}(1382-1760 \mathrm{~F})$ with a rate of rise in temperature of $30 \mathrm{C}(86 \mathrm{~F})$ per minute and then bench cooled. For glazing, the samples were preheated and then held at $960 \mathrm{C}(1760 \mathrm{~F})$ for two minutes without vacuum and bench cooled.

The Neydium porcelain samples were preheated in the open muffle of the furnace at $649 \mathrm{C}(1200 \mathrm{~F})$. The samples were then fired under a vacuum pressure of $635 \mathrm{~mm}$ ( $25 \mathrm{in})$ of mercury at a rate of rise in temperature of $38 \mathrm{C}(100 \mathrm{~F})$ per minute from 649-982 C (1200-1800 F) and then bench cooled under a beaker. For glazing the samples, the procedure for preheating and firing was repeated up to $982 \mathrm{C}(1800 \mathrm{~F})$, but without vacuum, and then bench cooled under a beaker.

The Willceram porcelain samples were preheated at $579 \mathrm{C}(1075 \mathrm{~F})$ for five $\mathrm{min}$ utes. The samples were fired in a vacuum of 660-736 $\mathrm{mm}(26-29 \mathrm{in})$ at a rate of rise in temperature of $34 \mathrm{C} \mathrm{(92} \mathrm{F)} \mathrm{per} \mathrm{minute} \mathrm{up} \mathrm{to}$ $910 \mathrm{C}(1670 \mathrm{~F})$ until a glossy surface was evident. For glazing, the samples were preheated at $560 \mathrm{C}(1040 \mathrm{~F})$ for six minutes at the same heating rate up to $899 \mathrm{C}(1650$ F), but without vacuum.

The Steele's APCO porcelain (1875) samples were preheated in front of the open furnace at $579 \mathrm{C}(1075 \mathrm{~F})$ for five minutes. The samples were then fired at atmospheric pressure at a heating rate of $21 \mathrm{C}(70 \mathrm{~F})$ per minute up to $968 \mathrm{C}(1775 \mathrm{~F})$. For glazing, the samples were heated to 1024 $\mathrm{C}(1875 \mathrm{~F})$ at the same heating rate and bench cooled.

The average thickness of each sample was obtained from five measurements along a diameter of the sample using a micrometer with point contacts.

For direct transmission measurements, an aluminum sample holder $(1.25 \mathrm{~cm} x$ $1.25 \mathrm{~cm} \times 4.5 \mathrm{~cm}$ ) with a hole of $8.5 \mathrm{~mm}$ diameter was used. The sample disk was held in place by brass rings (Fig. 2). The intensity of the direct transmission beam was measured in a dual beam spectrophotometer* with air as the reference. For total transmission measurements, an aluminum sample holder (Fig. 3), with the sample at the entrance port of the integrating sphere,

\footnotetext{
* Beckman Acta C III UV-visible spectrophotometer, Beckman Instruments, Inc., Irvine, CA 92664
} 


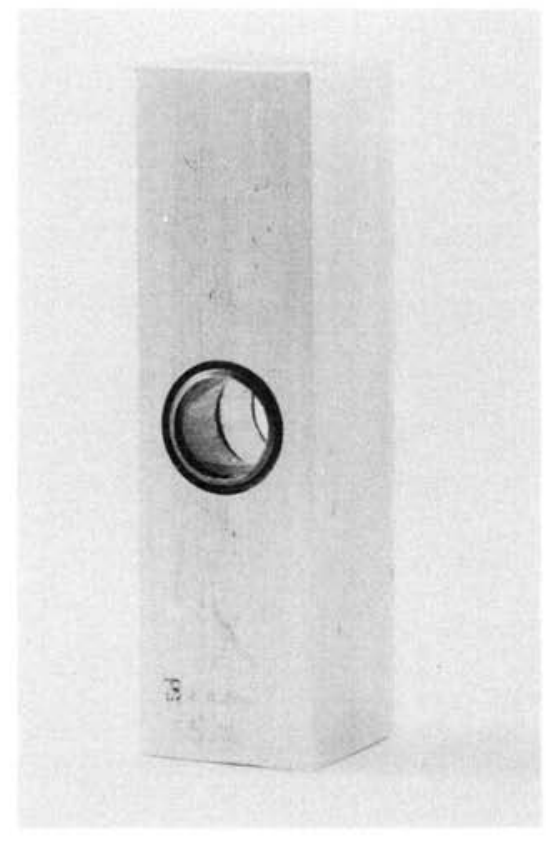

Fig. 2 - Sample holder for direct transmission measurement.

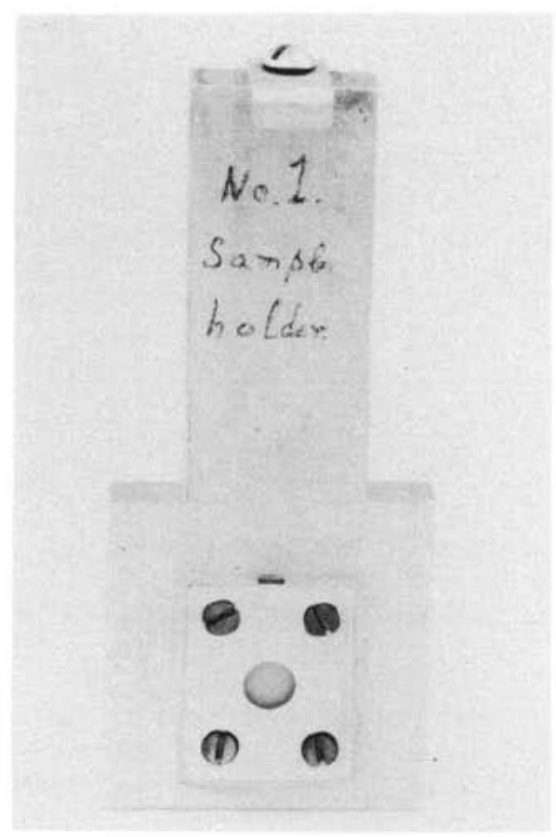

Fig. 3 - Sample holder for total transmission measurement. was used. Barium sulfate reflectance standards were used to complete the integrating sphere. The intensity of the total transmission was measured in a dual beam spectrophotometer with an integrating sphere assembly.* For both types of measurements, the intensity of the beam passing through the sample was continuously recorded for wavelengths from $700 \mathrm{~nm}$ to $400 \mathrm{~nm}$. Digital readings at $525 \mathrm{~nm}$ were also recorded and used for the calculations.

To establish the linear relationship between thickness of the porcelain samples and their transmission, three sections of varying thickness were cut from a larger sample of Ceramco incisor light porcelain $4 \mathrm{~mm}$ in width. Three sections, approximately $1.4,1.0$, and $0.8 \mathrm{~mm}$, were prepared with smooth parallel sides, using a slow speed precision saw ${ }^{\dagger}$ with a diamond wheel $0.4 \mathrm{~mm}$ thick. The total transmission of these samples was measured.

\section{Results.}

Total transmission values at $525 \mathrm{~nm}$ for the Ceramco incisal porcelain samples of different thicknesses are given in Fig. 4. The correlation coefficient of the linear regression line is 0.985 .

All porcelains showed increases in direct transmission with increasing wavelengths between 400 and $700 \mathrm{~nm}$. Representative spectra in direct transmission are shown in Fig. 5. No distinct peaks were observed in any spectrum. Table 2 shows the percent transmission through $1 \mathrm{~mm}$ of the porcelain samples in direct transmission using equation 1.

Representative spectra of total transmission of porcelain samples are shown in Fig. 6. All samples have similar spectra showing increasing transmission with increasing wavelengths from 400 to $700 \mathrm{~nm}$. The percentages of total transmission through $1 \mathrm{~mm}$ of the porcelain samples are given in Table 3 . The values were obtained using equation 1 . An analysis of variance showed that there were significant differences in the mean

*Beckman ACTA C III spectrophotometer with integrating sphere, Beckman Instruments, Inc., Irvine, CA 92664

†ISOmet 11-1180 Low Speed Precision Saw, Beuhler, Ltd., 2120 Greenwood Street, Evanston, IL 60204 
TABLE 1

BODY PORCELAINS AND EQUIVALENT SHADES

\begin{tabular}{|c|c|c|c|c|c|}
\hline Bioform & Ceramco B.F. ${ }^{\mathrm{a}}$ & Vita VMK ${ }^{b}$ & Neydiumc & Willceram ${ }^{\mathrm{d}}$ & Steeles ${ }^{e}$ \\
\hline $\begin{array}{l}59 \\
62 \\
65 \\
67 \\
91\end{array}$ & $\begin{array}{l}59 \\
62 \\
65 \\
67 \\
91\end{array}$ & $\begin{array}{l}\text { Al } \\
\text { NA } \\
\text { B3 } \\
\text { B4 } \\
\text { NA }\end{array}$ & $\begin{array}{l}\text { LY-2 } \\
\text { LC-3 } \\
\text { LC-3/LR-3 } \\
\text { DY-3/DC-3 } \\
\text { DY-1/DC-1 }\end{array}$ & $\begin{array}{l}59 \\
62 \\
65 \\
67 \\
\text { NA }\end{array}$ & $\begin{array}{l}61 \\
\text { NA } \\
65 \\
67 \\
\text { NA }\end{array}$ \\
\hline \multicolumn{6}{|c|}{$\begin{array}{l}\text { aCeramco B.F. Vacuum Porcelain } \\
\text { Ceramco, Inc., } 20 \text { Lake Dr., East Windsor, NJ } 08520\end{array}$} \\
\hline \multicolumn{6}{|c|}{$\begin{array}{l}\text { bVita VMK 68. Vacuum Porcelain } \\
\text { Unitek Corporation, } 2724 \text { South Peck Road, } \\
\text { Monrovia, CA } 91016\end{array}$} \\
\hline \multicolumn{6}{|c|}{$\begin{array}{l}\text { The J.M. Ney Company, Maplewood Avenue, } \\
\text { Bloomfield, CT } 06002\end{array}$} \\
\hline \multicolumn{6}{|c|}{$\begin{array}{l}\text { William Gold Refining Company, Inc., } \\
\text { Buffalo, NY } 14214\end{array}$} \\
\hline $\begin{array}{l}\text { eSteele } \\
\text { The C } \\
\text { Colur }\end{array}$ & $\begin{array}{l}\text { PCO Porcelain (1 } \\
\text { mbus Dental Mar } \\
\text { OH } 43206\end{array}$ & ring Company & & & \\
\hline
\end{tabular}

TABLE 2

TRANSMISSION \% ( $\mathrm{t}_{\mathrm{c} \text { (direct) }} \times 100$ ) AT $525 \mathrm{~nm}$ OF $1 \mathrm{~mm}$ THICK PORCELAINS IN DIRECT TRANSMISSION. STANDARD DEVIATIONS IN PARENTHESES.

\begin{tabular}{lccccc}
\hline \hline & Ceramco & Vita & Neydium & Willceram & Steeles \\
\hline 59 & $0.24(0.18)$ & $0.09(.07)$ & $0.29(0.29)$ & $0.07(0.04)$ & $0.11(0.08)$ \\
62 & $0.12(0.06)$ & - & - & $0.17(0.25)$ & - \\
65 & $0.04(0.04)$ & $0.06(0.08)$ & $1.08(0.69)$ & $0.28(0.28)$ & $0.07(0.06)$ \\
67 & $0.09(0.04)$ & $0.03(0.03)$ & $0.17(0.12)$ & $0.21(0.34)$ & $0.10(0.09)$ \\
91 & $0.15(0.04)$ & - & $1.13(0.76)$ & - & - \\
\hline
\end{tabular}

TABLE 3

TRANSMISSION \% ( $\left.t_{\text {c(total }} \times 100\right)$ AT $525 \mathrm{~nm}$ OF $1 \mathrm{~mm}$ THICK PORCELAINS IN TOTAL

TRANSMISSION USING THE INTEGRATING SPHERE. STANDARD DEVIATIONS IN PARENTHESES.

\begin{tabular}{lccccc}
\hline & Ceramco & Vita & Neydium & Willceram & Steeles \\
\hline 59 & $29.97(8.61)$ & $22.66(6.37)$ & $31.93(5.78)$ & $26.06(4.07)$ & $27.23(7.34)$ \\
62 & $27.85(3.90)$ & - & - & $27.88(9.95)$ & - \\
65 & $23.31(5.06)$ & $20.39(3.89)$ & $35.39(9.83)$ & $33.50(10.25)$ & $22.10(6.30)$ \\
67 & $26.32(1.53)$ & $18.04(5.18)$ & $23.58(3.95)$ & $19.03(4.77)$ & $23.42(3.77)$ \\
91 & $31.81(3.33)$ & - & $38.41(13.07)$ & - & - \\
\hline
\end{tabular}




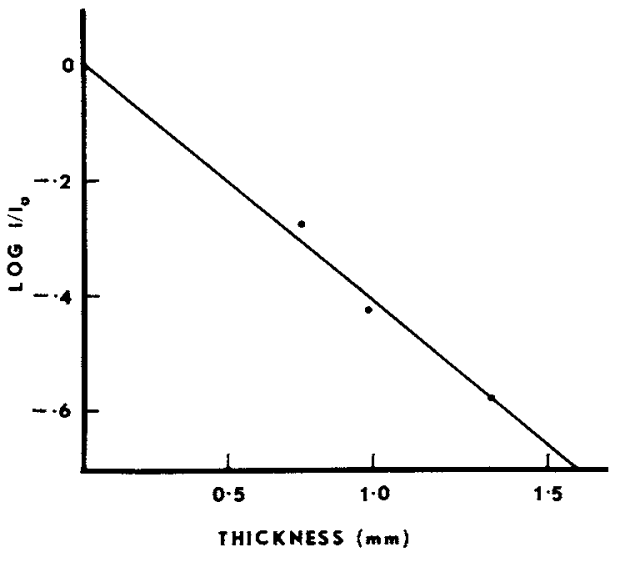

Fig. 4 - Total transmission of porcelain samples as a function of thickness.

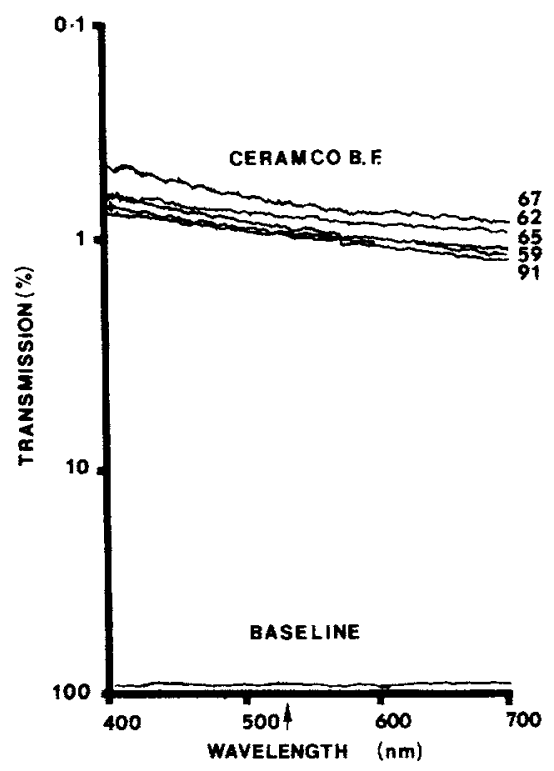

Fig. 5 - Transmission spectrum of a dental porcelain by direct transmission.

values for the percent transmission through $1 \mathrm{~mm}$ of the porcelain samples in total transmission with $\mathrm{P}<0.01$. Although the variances are high, they are homogeneous according to Bartlett's test. A StudentNewman-Keuls (SNK) test at $\alpha=0.05$ showed that the translucency of porcelains, by total transmission, can be ranked into two groups. One group has values ranging between 38.14 to $22.10 \%$, while the other

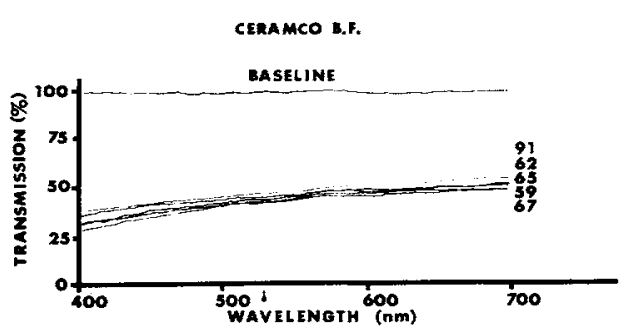

Fig. 6 - Transmission spectrum of a dental porcelain by total transmission (direct and diffuse).

group ranges from 35.39 to $18.04 \%$ under the same conditions. There were no significant differences among members of the same group. The only significant difference in translucency was between the most translucent porcelain, Neydium 91 (38.14\%), and the three least translucent porcelains: Vita 65 $(20.39 \%)$, Willceram $67(19.03 \%)$, and Vita $67(18.05 \%)$.

\section{Discussion.}

Translucency of dental porcelain is a function of sample thickness. The transmission of light through porcelain can be approximated by $I / I_{0}=t_{c}{ }^{x}$. The linear relationship between $\log I / I_{\circ}$ and sample thickness (Fig. 4) shows that $\mathrm{t}_{\mathrm{c}}$ can be used as a measure of the amount of light transmitted through a $1 \mathrm{~mm}$-thick porcelain sample with the incident beam at unit intensity.

The amount of light directly transmitted through porcelain samples is less than $1 \%$, whereas the amount of total transmission, which is the sum of directly transmitted light and diffuse transmission by scattering, averages $26.8 \%$. The results show that the main factor of translucency in dental porcelains is due to multiple scattering of light in the porcelain. Most dental porcelains incorporate opacifiers, such as tin oxide, as scattering centers to give a translucent appearance by diffuse transmission and scattering to improve the esthetics of porcelain restorations. ${ }^{12}$ Scattering of light decreases with increasing wavelength. This is in accordance with the Rayleigh scattering equation which states that higher scattering occurs at lower wavelengths. ${ }^{10}$ This would result in an increase in total transmission at 
higher wavelengths as was observed (Fig. 6).

There were significant differences in the total transmission coefficients $t_{c \text { (total) }}$ for values of the dental porcelains tested. Because of the relatively large error variances, ranking of the materials using the SNK test showed differences only in the extreme values.

\section{Conclusions.}

Transmission of light through a dental porcelain is dependent on its thickness. When the thickness is within a narrow range, around $1 \mathrm{~mm}$, the amount of light transmitted can be approximated as $I=I_{0} t_{c} x$ with $t_{c \text { (direct) for direct transmission and }}$ $t_{c \text { (total) }}$ for (direct and diffuse) transmission.

The translucency of a dental porcelain can be expressed in terms of a transmission coefficient for total transmission, $t_{c}$. There were statistically significant differences found among the values of $t_{c}$ for the porcelains used in this study.

Dental porcelains transmit 200 times more light by total transmission than by direct transmission. Also, total transmission increases with increasing wavelengths as stated by the Rayleigh scattering equation.

\section{Acknowledgment.}

The authors thank Dr. D. Dziewiatkowski and Dr. R. C. Yu for their cooperation.

\section{REFERENCES}

1. ADAIR, P.J.; PAMEIJER, C.H.; and GUILDENHUYS, R.R.: Reproduction of Metal
Ceramic Shades According to Prescribed Shade Guides, IADR Program Abstr Papers 34:909, 1976.

2. CULPEPPER, W.D.: A Comparative Study of Shade Matching Procedures, $J$ Prosthet Dent 24:166-74, 1970 .

3. PRESTON, J.D.: Color in Fixed Prosthodontics, Monograph, V.A. Wadsworth Hospital, Los Angeles, CA, 1974, $18 \mathrm{pp}$.

4. LOMBARDI, R.E.: The Principles of Visual Perception and Their Clinical Application to Denture Esthetics, J Prosthet Dent 29:358$82,1973$.

5. SPROULL, R.C.: Color Matching in Dentistry. Part II. Practical Applications of the Organization of Color, $J$ Prosthet Dent 29: 556-566, 1973.

6. SPROULL, R.C.: Color Matching in Dentistry. Part II. Color Control, $J$ Prosthet Dent 31: 146-54, 1974.

7. O'BRIEN, W.J.: Dental Porcelains. O'Brien, W. J. and Ryge, G. eds. An Outline of Dental Materials and Their Selection. Philadelphia: W. B. Saunders Co., 1978.

8. McLEAN, J.W.: The Science and Art of Dental Ceramics: Aesthetics of Dental Porcelains: Monograph III. Louisiana State University, School of Dentistry, New Orleans, 1976.

9. GETTLEMAN, L.; HERZBERG, T.W.; WEBBER, R.L.; and MOFFA, J.P.: Effect of Metal Surface Treatment on the Masking Power of Opaque Porcelain. Dental Porcelain: The State of the Art. Los Angeles: University of Southern California, 1977.

10. MORGAN, J.: Introduction to Geometric and Physical Optics. New York: McGraw-Hill Book Co., 1953.

11. SOKAL, R.R. and ROHLF, F.J.: Biometry. San Francisco: W.H. Freeman and Co., 1969 , pp 239-46.

12. O'BRIEN, W.J. and RYGE, G.: Relation Between Molecular Force Calculations and Observed Strengths of Enamel-metal Interfaces, $J$ Am Ceram Soc 47:5-8, 1964. 